O Open Access Full Text Article

ORIGINAL RESEARCH

\title{
Assessment of current clinical practices for major depression in Japan using a web-based questionnaire
}

This article was published in the following Dove Press journal: Neuropsychiatric Disease and Treatment

\author{
Hikaru Hori ${ }^{1}$ \\ Kentaro Yamato ${ }^{2}$ \\ 'Department of Psychiatry, University of \\ Occupational and Environmental Health, \\ Kitakyushu, Fukuoka, Japan; ${ }^{2}$ JPBU \\ Department of Medical Affairs, Takeda \\ Pharmaceutical Co. Ltd., Tokyo, Japan
}

Purpose: To investigate the current clinical practice of Japanese physicians in the diagnosis and management of major depression (major depressive disorder [MDD]).

Patients and methods: Japanese physicians specializing in psychiatry or psychosomatic medicine in the medical database of Nihon Ultmarc Inc. (Chuo-Ku, Tokyo, Japan), who had treated $\geq 30$ patients with MDD in the past month were invited to complete a web-based questionnaire from January 15 to 29,2018 . The questionnaire was comprised of 28 questions pertaining to the physician's background, the criteria and tools used to diagnose MDD during physician-patient consultation, and actual and preferred duration of physician-patient consultation. Responses were given as single answer numerical values or as multiple-choice answers.

Results: From the 518 physicians invited to participate, 340 completed questionnaires were analyzed. Respondents were predominantly male (90\%), hospital based (73\%), affiliated with the Department of Psychiatry (95\%), and members of the Japanese Society of Psychiatry and Neurology (87\%). The majority of physicians (84\%) agreed that "improvement of cognitive dysfunction caused by major depression is an important factor for patients to return to work" was the most challenging aspect of MDD diagnosis and management. Moreover, $83 \%$ of physicians conducted psychological assessments using a cognition evaluation test with most of their patients at the time of MDD diagnosis; the most commonly used tool was the Hasegawa Dementia Scale-Revised. Both hospital-based physicians and general practitioners would prefer to have longer consultations with their patients.

Conclusion: Physicians acknowledge the importance of the assessment and management of cognitive dysfunction in patients with MDD. However, most physicians would prefer to have longer consultation times with their patients for the diagnosis of MDD. In the future, it may be useful to introduce digital tools (eg, THINC-it ${ }^{\circledR}$ ) for the initial screening of cognitive dysfunction.

Keywords: Japan, survey, diagnosis, management, major depression disorder

\section{Introduction}

Major depression (major depressive disorder [MDD]) is a common, costly, and heterogeneous psychiatric disorder, associated with decreased social functioning and increased mortality. ${ }^{1-3}$ The 12-month prevalence of major depressive episodes in Japan is $2.2 \%$, which is lower than high-income countries, including the US $(8.3 \%)$, France $(5.9 \%)$, and Germany $(3.0 \%) .{ }^{1}$ However, the prevalence of MDD in Japan is suggested to be higher than reported, as MDD is often underdiagnosed and

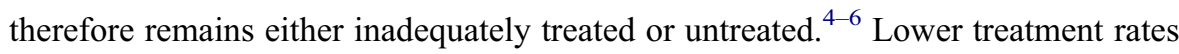

Correspondence: Kentaro Yamato JPBU Department of Medical Affairs, Takeda Pharmaceutical Co. Ltd.,

I-I Nihonbashi-honcho 2-chome,

Chuo-ku, Tokyo 103-8668, Japan

Tel +8I 332783244

Fax +8I 332782925

Email kentarou.yamato@takeda.com 
of MDD in Japan compared with high-income Western countries may be due, in part, to the stigma associated with mental illness in Japan. ${ }^{6}$

In 2010, MDD was the leading cause of disabilityadjusted-life-years and the second leading cause of years lived with disability. ${ }^{7}$ Severe MDD is a major contributor to suicide, which was a leading cause of death and accounted for approximately 788,000 deaths worldwide in $2015 .{ }^{8}$ Lack of adherence to antidepressants poses additional challenges. There is a strong association between non-adherence and worsening patient clinical and economic outcomes. ${ }^{9}$ It has been reported that patients non-adherent to antidepressant medication were more likely to experience suicidal ideation, and were at increased risk of relapse and/or recurrence, emergency department visits, hospitalization rates, and increased severity of depression. ${ }^{9}$ Several predictors of non-adherence have been reported including patient concerns about treatment-related side effects, medication dependence, and patients' beliefs, clinical factors (lack of patients education and follow-up), and social factors (isolation, poverty, lack of social support, low income, and educational level). ${ }^{10-14}$ In addition to these, Pompili et al have reported younger age ( $<40$ years), comorbidity with substance use and personality disorders, severity of illness, and poor therapeutic alliance between the patient and physician as indicators of non-adherence. ${ }^{15}$ Given the high social, clinical, and economic impact of non-adherence among patients who are affected by mood disorders it is imperative to identify key predictors in order to recognize patients at risk for non-adherence. ${ }^{15}$

MDD is diagnosed by the appearance of mood disturbances; however, a multitude of symptoms are often present, and there is accumulating evidence that symptomatic treatment for mood disturbances may be insufficient for the treatment of MDD. ${ }^{16-19}$ Cognitive dysfunction has been associated with psychosocial dysfunction and work impairment, including decreased work productivity and/or increased absenteeism. ${ }^{16,20-23}$ Evidence suggests that management of cognitive function may improve patient outcomes in MDD. ${ }^{16}$

In recent years, guidelines have been generated and revised to standardize diagnostic tools for the diagnosis of psychiatric disorders. ${ }^{20,24-27}$ Efforts have been made to determine clinical practices in the diagnosis of cognitive function in patients with MDD. For example, a web-based questionnaire targeting psychiatrists in the USA, France, Germany, Spain, Australia, and Hong Kong examined how physicians assessed cognitive function among their patients with MDD $;{ }^{20}$ however, cognitive evaluation was difficult to determine because of reliance on patient history rather than cognitive evaluation tools. ${ }^{20}$ In Japan, there are a number of evaluation tools that can be used to measure MDD as well as cognitive function, including the Hamilton Depression Rating Scale (HAM-D), Montgomery-Åsberg Depression Rating Scale (MADRS), and Digit Symbol Substitution Test (DSST). The Perceived Deficits QuestionnaireDepression (PDQ-D) test is also available, however the Japanese version had not been validated at the time of the current survey. ${ }^{28}$ We therefore designed a web-based questionnaire to investigate current clinical practice in the diagnosis and management of MDD. Our questionnaire included sections that focused on the challenges of accurate diagnosis and disease management of MDD; evaluation tools used for psychological and cognitive assessments; active assessments of physiological and psychological parameters of patients; and the duration of initial and follow-up consultations.

\section{Materials and methods}

\section{Study design}

This was a population-based, prospective, observational study conducted from January 15 to 29,2018 . Physicians in Japan were asked to complete a web-based questionnaire, which consisted of five sections and a total of 28 questions. There were two to seven questions per section pertaining to: 1) physician background (including the type of facility they practiced in, physicians age, expertise, and departmental affiliation); 2) criteria used to assess and diagnose MDD during patient consultation; 3) evaluation tools used to assess patients and their frequency of use; and 4) whether physicians were aware of cognitive dysfunction as a symptom of MDD and whether physicians actively diagnosed and managed such symptoms. Responses were given as single answer numerical values or as multiple-choice answers.

The questionnaire was delivered to physicians using a Social information service (Social Survey Research Information Co. Ltd., Tokyo, Japan) via Japan's medical professional website m3.com (https://www.m3.com/). Participants could save partially completed questionnaires for completion by January 29, 2018. The minimum number of responses by January 29, 2018 was set as 300 .

Sample questionnaires are included in the supplementary materials (Tables $\mathrm{S} 1$ and $\underline{\mathrm{S} 2}$ ). 


\section{Study population}

Hospital physicians and general practitioners who were registered on m3.com (https://www.m3.com/) were invited to participate in the survey. Physicians were screened via the Marc Inc. database in Japan and invited to participate if they were registered as specializing in psychiatry (code O01) or psychosomatic medicine (code A82) in the medical database of Nihon Ultmarc Inc. (Chuo-Ku, Tokyo, Japan), and had treated a minimum of 30 patients with MDD in the past month. There were no age restrictions.

Respondents consented to personal information protection guidelines, which stated that any information disclosed could not be used to identify individuals. All responses were anonymized. Physicians were not required to enter their name or other personal details. Due to multiple-choice or numerical response options, personal information of patients could not be disclosed. Due to the absence of direct patient involvement and clinical data ethics, approval was not required.

\section{Objectives}

The primary objective was to examine the clinical practice of physicians in relation to the diagnosis and management of MDD in Japan. It can be hypothesized that 1) issues surrounding the clinical practice of MDD may differ depending upon the physicians' facilities, age, expertise, and participation in academic societies, 2) the diagnostic approach for MDD may not be standardized, 3) the use of the assessment batteries for MDD may be limited, 4) there may only be a small number of physicians who refer to the Japanese Society of Mood Disorders treatment guidelines, ${ }^{24}$ and 5) clinical practices that consider cognitive impairment in MDD may be limited.

\section{Statistical analysis}

Completed questionnaires were excluded if completed within 2 mins, or if the answers to a select number of questions were identical. Results were presented descriptively as percentages of physicians responding to the options provided for each question. Factors relating to: challenges in the clinical diagnosis and management of MDD; evaluation tools used for the diagnosis of MDD and assessment of cognitive dysfunction; and psychological and physiological parameters assessed for the diagnosis of MDD; and duration of initial and follow-up consultations, were assessed using the chi-squared test by physician facility. Physicians practicing at clinics were defined as general practitioners and those working in other facilities were categorized as hospital physicians. All statistical analyses were performed on Microsoft ${ }^{\circledR}$ Excel by Social Survey Research Information Co. Ltd.

\section{Results}

\section{Physician background and demographics}

A total of 518 physicians identified in the m3.com database (https://www.m3.com/) completed questionnaires. Of these, 164 questionnaires were excluded for the following reasons: the physician reported no adverse events $(n=13)$, the clinical department was listed as "other" $(n=25)$, the number of patients seen with MDD were $<30$ patients $(n=119)$, or the questionnaire was not fully completed $(\mathrm{n}=7)$. Of the remaining 354 completed questionnaires, 14 were excluded for the following reasons: the number of patients was $>2000(n=1)$, the duration of the initial visit was shorter than follow-up ( $\mathrm{n}=2)$, the questionnaire was completed within 3 mins $(n=9)$, or the answers to questions 12, 14, 15, 16, 27, and 28 were the same $(\mathrm{n}=2)$. The remaining 340 completed questionnaires were included in the analysis. Responding physicians were predominantly male $(90 \%)$, hospital-based $(73 \%)$, worked in a city or urban area $(77 \%)$, affiliated with a department or advertised their specialty as psychiatry $(95 \%)$, or members of the Japanese Society of Psychiatry and Neurology (87\%; Table 1). In addition, $47 \%$ of respondents were hospital physicians at psychiatric hospitals, $40.3 \%$ had treated between 30 and 49 patients in the past month, $36 \%$ had 10-19 years of experience in psychiatric treatment, and were predominantly in the 30-39 year-old, and 40-49 year-old age group (both 34\%; Table 1). The median and mean time taken to complete the questionnaire was 6 and 32 mins, respectively. The variation was observed because physicians could save and later return to complete the questionnaire.

\section{Challenges in the clinical diagnosis and management of MDD}

Of the 340 physicians, 285 (84\%) agreed that "Improvement of cognitive dysfunction caused by major depression is an important factor for patients to return to work" was the most challenging clinical task in the diagnosis and management of MDD. In addition, $59 \%$ of physicians agreed that "Clinical manifestations alone are insufficient to understand individual symptoms" (Figure 1). There were no significant differences between hospital physicians and general practitioners 
Table I Background and demographic characteristics

\begin{tabular}{|c|c|}
\hline & $\begin{array}{l}\text { Physicians, } \\
\text { n (\%) } \\
(\mathrm{N}=340)\end{array}$ \\
\hline \multicolumn{2}{|l|}{ Background } \\
\hline \multicolumn{2}{|l|}{ Sex } \\
\hline Male & $306(90)$ \\
\hline \multicolumn{2}{|l|}{ Age in years } \\
\hline$\leq 29$ & $6(2)$ \\
\hline $30-39$ & $65(19)$ \\
\hline $40-49$ & II4 (34) \\
\hline $50-59$ & $116(34)$ \\
\hline$\geq 60$ & $39(\mathrm{II})$ \\
\hline \multicolumn{2}{|l|}{$\begin{array}{l}\text { Years of experience of psychiatric disorder } \\
\text { assessment }\end{array}$} \\
\hline$\leq 3$ & $5(1)$ \\
\hline $3-9$ & $43(13)$ \\
\hline $10-19$ & $|2|(36)$ \\
\hline $20-29$ & $112(33)$ \\
\hline$\geq 30$ & $59(17)$ \\
\hline \multicolumn{2}{|l|}{$\begin{array}{l}\text { Number of patients with MDD treated in the past } \\
\text { month }\end{array}$} \\
\hline $30-49$ & $137(40.3)$ \\
\hline $50-99$ & $107(31.5)$ \\
\hline $100-199$ & $64(18.8)$ \\
\hline $200-299$ & $16(4.7)$ \\
\hline$\geq 300$ & $16(4.7)$ \\
\hline \multicolumn{2}{|l|}{ Facility } \\
\hline \multicolumn{2}{|l|}{ Type } \\
\hline University hospital & $40(12)$ \\
\hline Psychiatric hospital & $159(47)$ \\
\hline General hospital & $48(14)$ \\
\hline Clinic & $93(27)$ \\
\hline \multicolumn{2}{|l|}{ Number of hospital beds in entire facility } \\
\hline$\leq 19$ & $93(27)$ \\
\hline $20-99$ & $7(2)$ \\
\hline $100-199$ & $35(10)$ \\
\hline $200-299$ & $70(21)$ \\
\hline $300-499$ & $83(24)$ \\
\hline $500-799$ & $31(9)$ \\
\hline$\geq 800$ & $21(6)$ \\
\hline \multicolumn{2}{|l|}{ Location $^{\mathrm{a}}$} \\
\hline Urban area & $262(77)$ \\
\hline Other & $78(23)$ \\
\hline \multicolumn{2}{|l|}{ Departmental affiliation and society memberships } \\
\hline \multicolumn{2}{|l|}{ Departmental affiliation } \\
\hline Psychiatric & $324(95)$ \\
\hline Psychosomatic & $16(5)$ \\
\hline
\end{tabular}

(Continued)
Table I (Continued).

\begin{tabular}{|l|l|}
\hline & $\begin{array}{l}\text { Physicians, } \\
\text { n (\%) } \\
(\mathbf{N = 3 4 0 )}\end{array}$ \\
\hline $\begin{array}{l}\text { Graduate medical department } \\
\text { Psychiatry }\end{array}$ & $324(95)$ \\
Psychosomatic & $12(4)$ \\
Others & $4(1)$ \\
\hline $\begin{array}{l}\text { Society membership } \\
\text { The Japanese Society of Psychiatry and Neurology }\end{array}$ & $297(87)$ \\
Japanese Society of Mood Disorders & $50(15)$ \\
The Japanese Society of Clinical & $29(9)$ \\
Neuropsychopharmacology & $23(7)$ \\
The Japanese Society of Neuropsychopharmacology & $14(4)$ \\
Japanese Association of Behaviour Therapy & $92(27)$ \\
Other & $29(9)$ \\
None & 29 \\
\hline
\end{tabular}

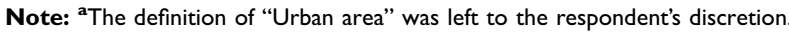
Abbreviation: MDD, major depressive disorder.

in their responses (Figure S1). For example, $85 \%$ of hospital physicians and $81 \%$ of general practitioners agreed that the factor most challenging in clinical practice was the treatment of MDD-caused cognitive dysfunction, which is important for patients to return to work (Figure S1).

\section{Assessments for the diagnosis of MDD}

The majority of physicians ( $\mathrm{n}=281 ; 83 \%$; Figure $2 \mathrm{~A}$ ) stated that they conducted psychological tests using an assessment tool with all or most of their patients at the time of mood disorder diagnosis. More than $50 \%$ of physicians were aware of, and performed, the Hasegawa Dementia Scale-Revised (HDS-R), Mini-Mental State Examination (MMSE), Zung Self-Rating Depression Scale (SDS), and HAM-D at time of mood disorder diagnosis (Figure 2B); whereas, overall, the Young Mania Rating Scale (YMRS), MADRS, Quick Inventory of Depressive Symptomatology-Japan (QIDS-J), and DSST were used by less than approximately $20 \%$ of physicians (Figure 2B). Hospital physicians were significantly more likely to use evaluation tools than general practitioners $(P$ value of $<0.001$ to 0.029 ; Figure $2 \mathrm{C}$ ). A small but significantly higher proportion of hospital physicians used the MADRS (21\%) compared with general practitioners (10\%; $P=0.015$; Figure 2C); whereas neither group often or regularly used the DSST (hospital physician: 5\%; general practitioners: $2 \%$; Figure $2 \mathrm{C}$ ). 


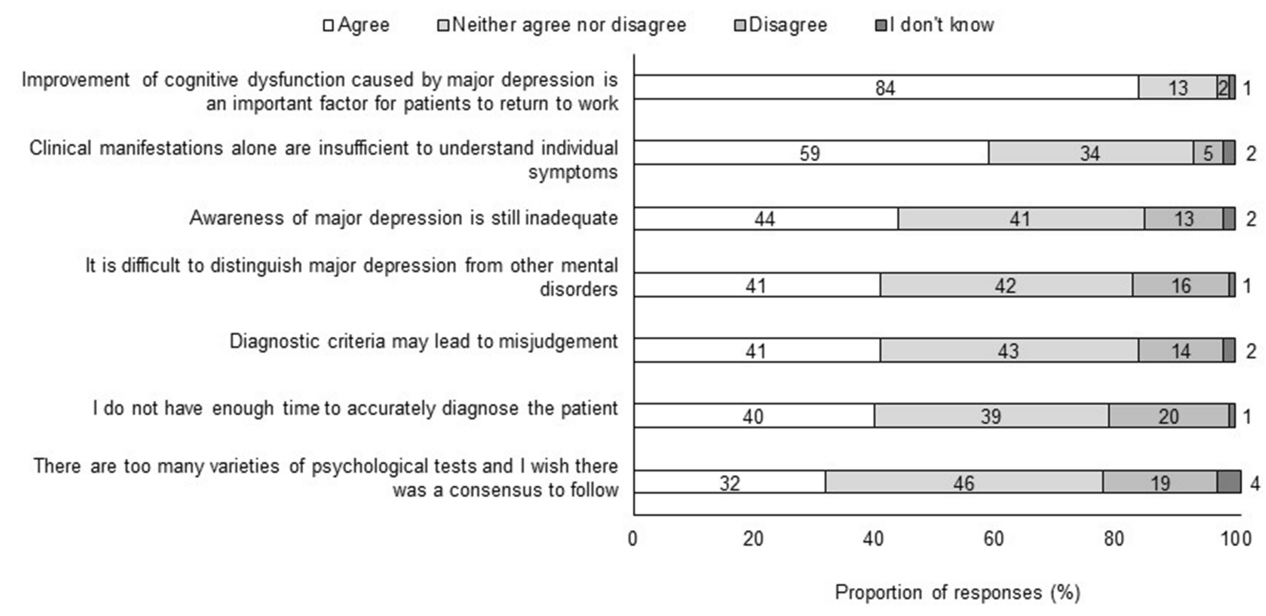

Figure I Challenges in the clinical diagnosis and management of MDD.

Notes: The question addressed was: regarding the medical care of major depression, please provide us with how much you agree or disagree with the following statements. Analyses were conducted on data from question 28 (Table SI). Responses from all hospital physicians and general practitioners were included ( $\mathrm{N}=340$ ).

Abbreviation: MDD, major depressive disorder.

At diagnosis, the top three most assessed psychological and physiological parameters by physicians were: the patient's history of mental illness $(91 \%)$, sleep patterns (91\%), and background (89\%; development, academic, and employment history, and marital status) (Figure 3A). Hospital physicians conducted significantly more physiological tests than general practitioners (all $P<0.001$ ) (Figure 3B). Types of physiological tests conducted included, basic physiological tests (eg, height, weight, vital signs), blood and urine tests, other physiological tests (scans, eg, electrocardiogram, electroencephalogram), and imaging (computed tomography, magnetic resonance imaging, and/or single photo emission computed tomography). There were no significant differences between hospital physicians and general practitioners with regard to the psychological tests that they performed during the initial diagnostic assessment by physician facility (Figure 3B).

\section{Consultation duration for initial and follow-up visits}

The mean most common duration of the initial consultation visit was approximately $30 \mathrm{mins}$, although physicians would ideally spend 45 mins or longer on the initial consultation (Figure 4A). Furthermore, $40 \%$ of physicians agreed that the duration of the initial visit was insufficient to make an accurate diagnosis. There was no significant difference between hospital physicians and general practitioners in the actual duration of the initial consultation
( $P=0.462$; Figure 4B); however, further analysis demonstrated that hospital physicians' preferences regarding the ideal duration of the consultation were significantly different compared with that of general practitioners $(P=0.008)$. The ideal duration of consultation preferred by $39 \%$ of hospital practitioners was $>1 \mathrm{hr}$ compared with $22 \%$ of general practitioners $(P=0.003)$, and $41 \%$ of general practitioners preferring approximately 30 mins compared with $25 \%$ of hospital physicians $(P=0.003)$.

The mean most common consultation duration at follow-up was 5 mins; however, similar to the results for initial visits (Figure 4), physicians would ideally have longer consultation durations than currently available at followup (10 mins; Figure 5).

\section{Discussion}

Cognitive dysfunction affects patients at varying degrees during phases of MDD. ${ }^{29}$ Improvements in cognitive dysfunction are essential to improve patient outcomes, and therefore advances in assessing cognitive dysfunction are imperative. Such developments are not only important in Japan but also on a global scale given that depressive disorders are ranked as the single largest contributor to non-fatal decline in health worldwide $(7.5 \%$ of all years lived with disability). ${ }^{8}$ Our findings highlight important challenges to the diagnosis and management of MDD in Japan, which can be targeted to improve future clinical practice.

Overall, our study revealed that the majority of physicians valued the importance and challenges of diagnosis 
A

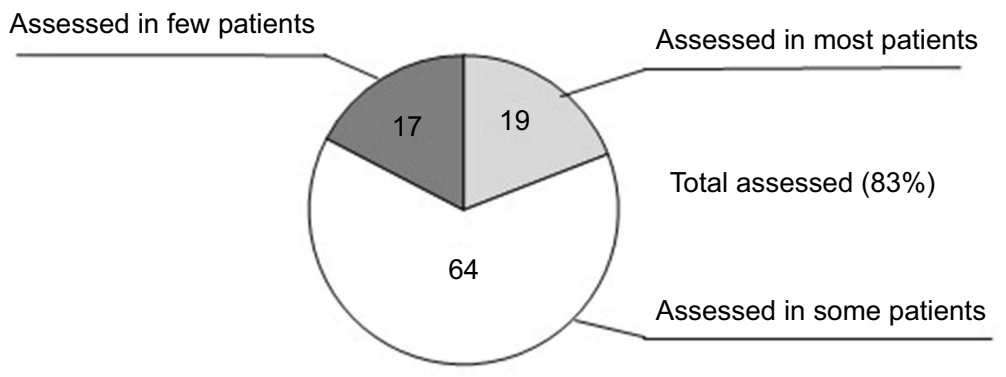

B al do not know this test

口I know this test, but it is not performed at time of diagnosis

al know this test and it may be performed at time of diagnosis

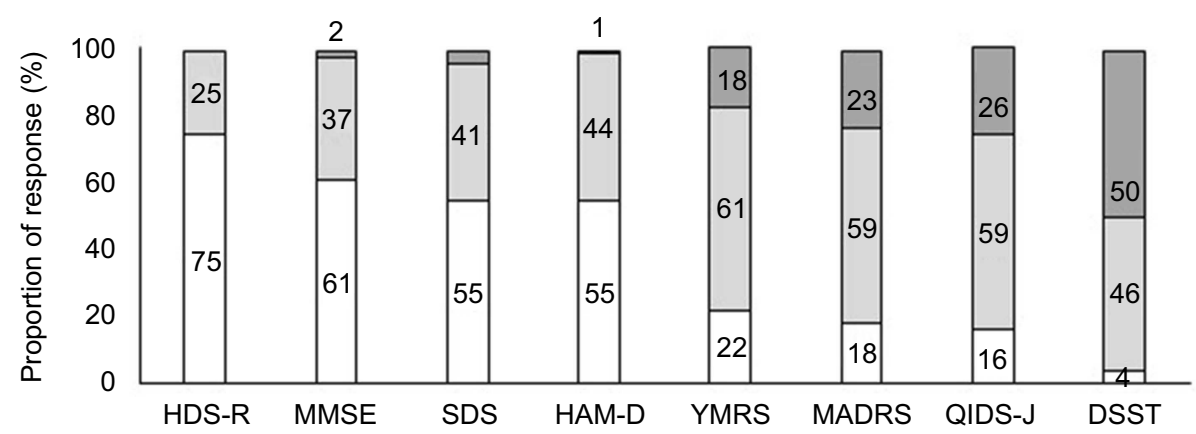

C

\begin{tabular}{llll}
\hline & \multicolumn{2}{c}{$\begin{array}{c}\text { Proportion of physicians who answered "I know this } \\
\text { test and it may be performed at time of diagnosis" }\end{array}$} \\
\cline { 2 - 4 } Test & Hospital physicians & General practitioners & Two-sided $P$-value \\
& $\mathbf{n}=\mathbf{2 4 7}$ & $\mathbf{n}=\mathbf{9 3}$ & \\
\hline HAM-D & $62 \%$ & $37 \%$ & $P<0.001^{* *}$ \\
SDS & $54 \%$ & $57 \%$ & 0.651 \\
MADRS & $21 \%$ & $10 \%$ & $P=0.015^{*}$ \\
QIDS-J & $18 \%$ & $9 \%$ & $P=0.029^{*}$ \\
YMRS & $26 \%$ & $10 \%$ & $P<0.001^{* *}$ \\
DSST & $5 \%$ & $2 \%$ & 0.263 \\
HDS-R & $75 \%$ & $74 \%$ & 0.833 \\
MMSE & $66 \%$ & $48 \%$ & $P=0.002^{* *}$ \\
\hline
\end{tabular}

Figure 2 Psychological assessments employed for the diagnosis of MDD.

Notes: (A) Proportion of physicians who employ psychological assessments. The question addressed was: in how many patients do you confirm and/or perform the following tests when you are diagnosing mood disorders? Analyses were conducted on data from question 14 (Table SI), and responses from all hospital physicians and general practitioners were included $(\mathrm{N}=340)$. (B) Psychological tests used to diagnose patients (all physicians). The question addressed was: are you aware of the following psychological tests? Do you perform these tests in clinical practice, when diagnosing a mood disorder? Analyses were conducted on data from question 15 (Table SI) and responses from all hospital physicians and general practitioners were included $(\mathrm{N}=340)$. (C) Psychological tests employed by physician facility. Analyses were conducted on data from question 15 (Table SI). Two-sided P-value was calculated using hypothesis testing for the difference in the population proportions $(* P<0.05 ; * * P<0.01)$.

Abbreviations: DSST, Digit Symbol Substitution Test; HAM-D, Hamilton Depression Rating Scale; HDS-R, Hasegawa Dementia Scale-Revised; MADRS, MontgomeryÅsberg Depression Rating Scale; MMSE, Mini-Mental State Examination; QIDS-J, Quick Inventory of Depressive Symptomatology-Japan; SDS, Zung Self-Rating Depression Scale; YMRS, Young Mania Rating Scale; MDD, major depressive disorder 
A

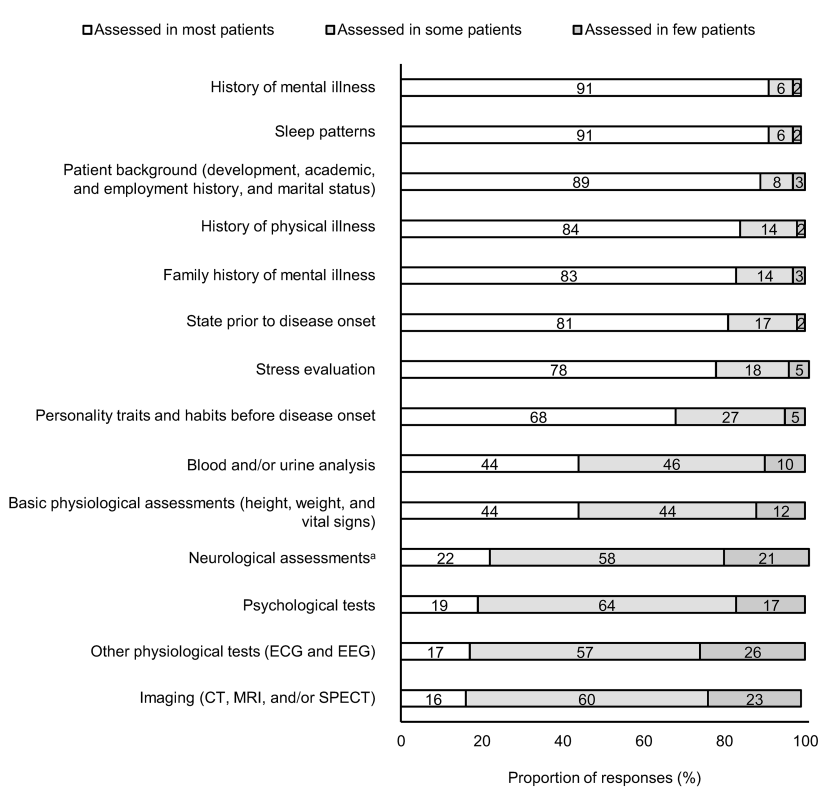

B

\begin{tabular}{|c|c|c|c|}
\hline \multirow{3}{*}{$\begin{array}{l}\text { Psychological and physiological } \\
\text { parameters }\end{array}$} & \multicolumn{3}{|c|}{$\begin{array}{l}\text { Proportion of physicians who answered } \\
\text { "Assessed in most patients" }\end{array}$} \\
\hline & $\begin{array}{l}\text { Hospital } \\
\text { physicians }\end{array}$ & $\begin{array}{l}\text { General } \\
\text { practitioners }\end{array}$ & Two-sided $P$-value \\
\hline & $\mathrm{n}=247$ & $\mathrm{n}=93$ & \\
\hline $\begin{array}{l}\text { Basic physiological assessments } \\
\text { (height, weight, and vital signs) }\end{array}$ & $51 \%$ & $27 \%$ & $P<0.001^{* *}$ \\
\hline Neurological assessments $\mathrm{a}^{\mathrm{a}}$ & $24 \%$ & $15 \%$ & 0.066 \\
\hline History of mental illness & $91 \%$ & $92 \%$ & 0.685 \\
\hline History of physical illness & $85 \%$ & $81 \%$ & 0.379 \\
\hline Family history of mental illness & $84 \%$ & $80 \%$ & 0.358 \\
\hline $\begin{array}{l}\text { Patient background (development, } \\
\text { academic, and employment } \\
\text { history, and marital status) }\end{array}$ & $90 \%$ & $86 \%$ & 0.314 \\
\hline $\begin{array}{l}\text { Personality traits and habits } \\
\text { before disease onset }\end{array}$ & $69 \%$ & $65 \%$ & 0.406 \\
\hline State prior to disease onset & $81 \%$ & $81 \%$ & 0.946 \\
\hline Stress evaluation & $77 \%$ & $78 \%$ & 0.818 \\
\hline Sleep patterns & $91 \%$ & $90 \%$ & 0.733 \\
\hline Blood and/or urine analysis & $55 \%$ & $16 \%$ & $P<0.001^{* *}$ \\
\hline $\begin{array}{l}\text { Other physiological tests (ECG } \\
\text { and EEG) }\end{array}$ & $22 \%$ & $4 \%$ & $P<0.001^{* \star}$ \\
\hline Imaging (CT, MRI, and/or SPECT) & $21 \%$ & $5 \%$ & $P<0.001^{* *}$ \\
\hline Psychological tests & $18 \%$ & $23 \%$ & 0.319 \\
\hline
\end{tabular}

Figure 3 Psychological and physiological parameters assessed at the time of MDD diagnosis.

Notes: (A) All physicians. The question addressed was: in how many patients do you confirm and/or perform the following tests when you are diagnosing mood disorders? Analyses were conducted on data from question 14 (Table SI) and responses from all hospital physicians and general practitioners were included $(\mathrm{N}=340)$. (B) By physician facility. Analyses were conducted on data from question 14 (Table SI) $(* * P<0.01)$. ${ }^{a}$ Neurological assessments included consciousness/mental state, language, cranial nerve examinations, motor, sensory and reflex system tests, coordination movement, meningeal irritation signs, posture, autonomic system assessments. ${ }^{43} \mathrm{Two}$-sided $P$-value was calculated using hypothesis testing for the difference in the population proportions.

Abbreviations: CT, computed tomography; ECG, electrocardiogram; EEG, electroencephalogram; MRI, magnetic resonance imaging; SPECT, single photo emission computed tomography; MDD, major depressive disorder.

and management of cognitive dysfunction in patients with MDD, and agreed that clinical manifestations alone were insufficient to understand individual symptoms. Moreover, most physicians performed psychological tests to examine cognitive function in patients, with the HDS-R being the most popular. Notably, there was a discrepancy between most common and ideal consultation duration for MDD diagnosis.

The key symptoms of MDD include physical manifestations (eg, decreased energy and sleep disturbance) and cognitive symptoms (eg, decreased motivation and difficulty with concentration). ${ }^{30}$ Clinical and patient perspective studies suggest that cognitive dysfunction is the primary cause of functional impairment. ${ }^{16,19,28,30,31}$ In a previous web-based questionnaire by El Hammi et al, 93\% of physicians assessed cognition in MDD. In accordance with this, the majority of physicians in the current study (84\%) agreed that improvement of cognitive dysfunction caused by MDD was an important factor in assisting patients to return to work and the most challenging clinical task in the diagnosis and management of MDD (Figure 1). However, MDD is a heterogeneous disorder, with multiple psychological tests used for assessing cognitive dysfunction subjectively (eg, MADRS), and objectively (DSST). ${ }^{29,32}$ Cognitive tests to assess cognitive dysfunction are not described in available guidelines; ${ }^{24,25}$ however, $59 \%$ of physicians in our study agreed that clinical manifestations alone were insufficient to understand individual patient's symptoms in MDD. Most Japanese physicians used psychological tests to assess cognitive dysfunction in their patients (Figure 2A). The HDS-R was the most widely known and used test (Figure 2B). One major reason for the popularity of tests such as HDS-R and MMSE may partially be due to a combination of the aging Japanese population, and the need to distinguish dementia and MDD in older patients. Other tests such as the SDS may be used more often than others, as physicians are reimbursed. Of note, the MADRS, QIDS-J, and DSST assessments are among those that can evaluate aspects of cognitive function in MDD; however, they are the least acknowledged and performed (Figure 2B). The DSST is a simple and easy-to-use test for cognition (assessing a combination of processing speed, working memory, attention and executive function) in MDD, as well as brain damage, and dementia. ${ }^{28,33-35}$ The low acknowledgment and use of the test may be because it does not screen for disease or provide 
A

口Most common duration aldeal duration

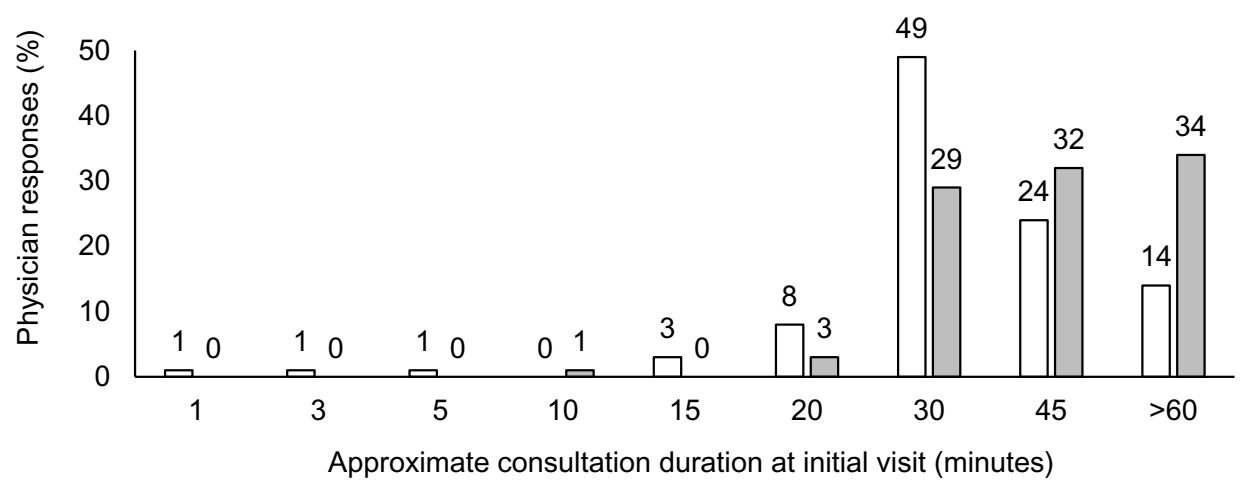

B
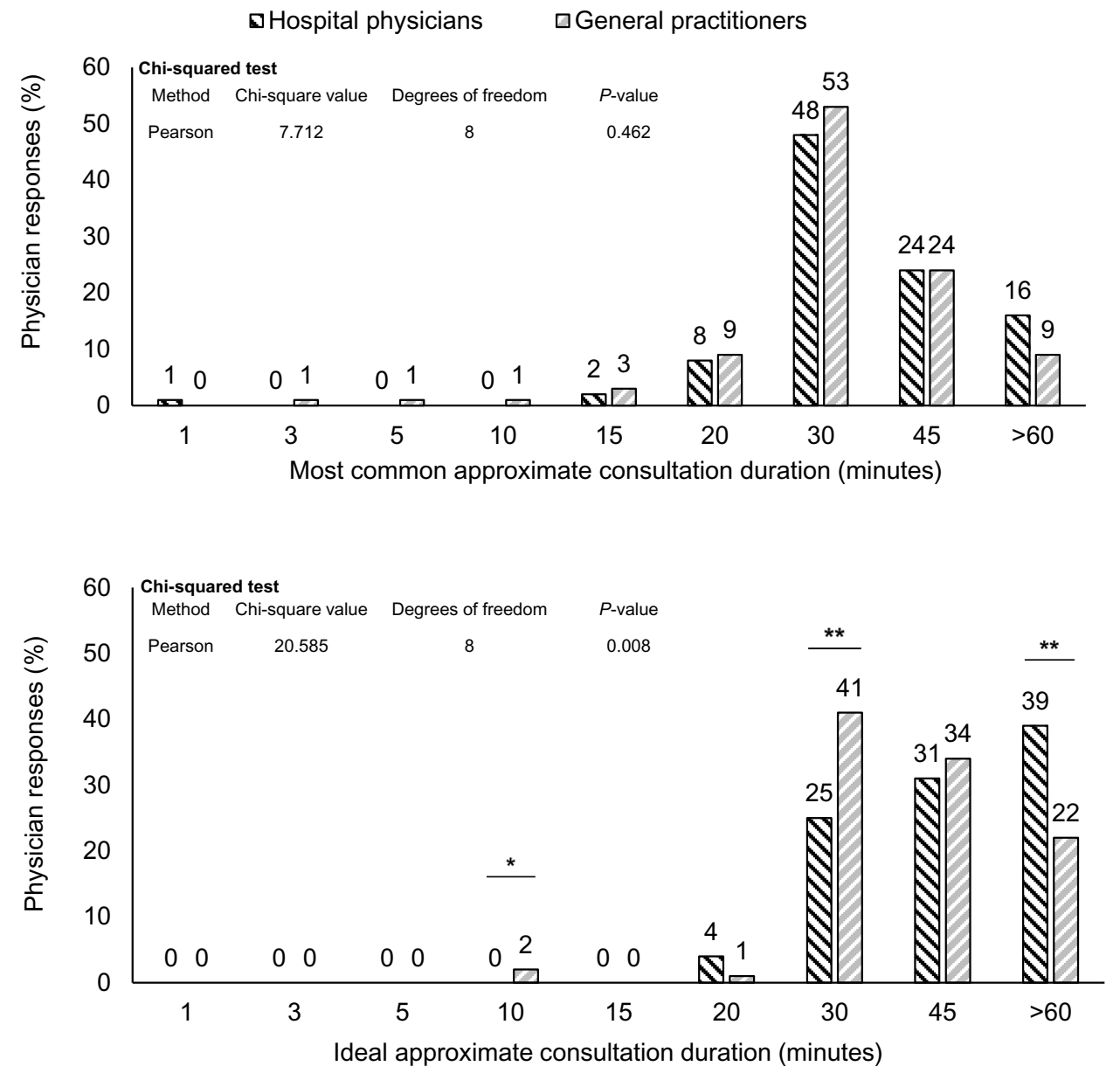

Figure 4 Most common and ideal consultation duration at initial visit.

Notes: (A) All physicians. The question addressed was: what is the most common consultation duration for your patients with major depression? What is the ideal consultation duration for an accurate diagnosis and evaluation? Analyses were conducted on data from question 19 (Table $\mathrm{SI}$ ) and responses from all hospital physicians and general practitioners were included $(\mathrm{N}=340)$. Consultation durations are approximate lengths. (B) By physician facility. Analyses were conducted on data from question 19 (Table SI) $(* P=0.021 ; * * P=0.003)$. Consultation durations are approximate lengths.

insurance reimbursement in Japan, like other tests such as the SDS.

Hospital physicians were significantly more likely to know and use the psychological tests HAM-D, MADRS, QIDS-J,
YMRS, and MMSE during mood disorder diagnosis than general practitioners ( $P$-value between $<0.001$ and 0.029 ). The differences observed in this study between hospital physicians and general practitioners may be because clinical 


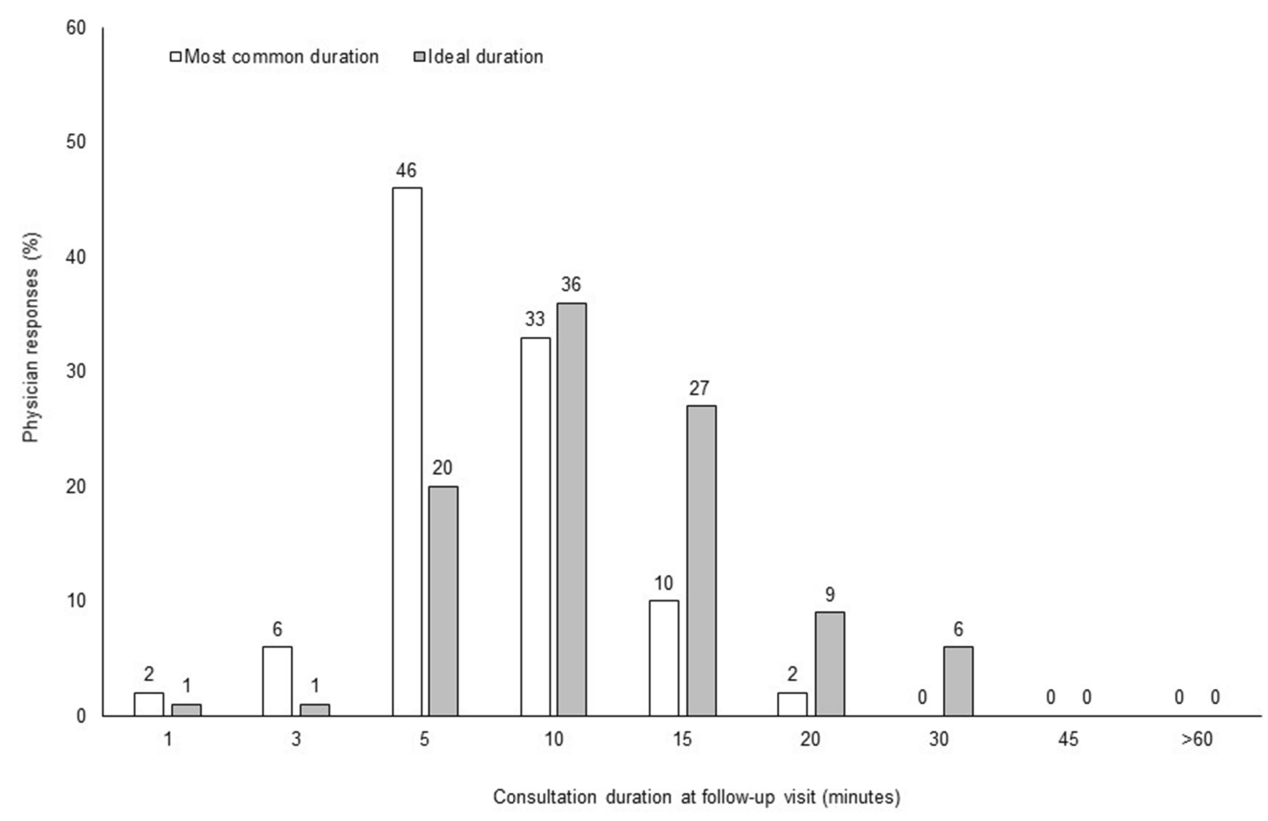

Figure 5 Most common and ideal consultation duration for follow-up visit.

Notes: The question addressed was: what is the most common consultation duration for your patients with major depression? What is the ideal consultation duration for an accurate diagnosis and evaluation. Analyses were conducted on data from question 19 (Table $\mathrm{SI}$ ) and responses from all hospital physicians and general practitioners were included $(\mathrm{N}=340)$. Consultation durations are approximate lengths.

research is often performed in hospitals versus clinics. Additionally, hospital physicians examined physiological parameters significantly more often than general practitioners at the time of diagnosis, with $<20 \%$ of general practitioners conducting blood and/or urine analysis, neurological assessments, scans, and imaging. This discrepancy may be due to the differences between routine examinations at a hospital versus a clinic and the lack of accessibility of facilities, eg, imaging tools.

Notably, both hospital physicians and general practitioners preferred to have longer initial and follow-up than actual consultation duration. Although the most common consultation length was comparable between hospital physicians and general practitioners, hospital physicians preferred to have significantly longer consultation length at first visit compared with general practitioners $(P=0.008)$. One possible reason for this difference may be because patients with severe MDD are more likely to visit a hospital than a clinic and thus, require more time for a differential diagnosis. In addition, physicians may not be using some tests due to limited duration of consultation with patients. For example, the HAM-D test takes approximately 20-40 mins to complete (Table 2). It may be useful to introduce digital tools for the initial screening of cognitive dysfunction. THINC-it ${ }^{\circledR}$ (http://thinc.progress.im/en/content/thinc-it-tool) is a cognitive functioning screening tool that assesses subjective and
Table 2 Average times taken to perform cognitive-behavioral tests

\begin{tabular}{|l|l|}
\hline Test & Time taken (minutes) \\
\hline HDS-R $^{39}$ & Approximately 10 \\
MMSE $^{40 *}$ & $10-15$ \\
SDS $^{*}$ & $10-15$ \\
HAM-D & \\
YMRS $^{42}$ & $20-40$ \\
MADRS $^{*}$ & $15-30$ \\
QIDS-J* $^{*}$ & $20-40$ \\
DSST* & $10-15$ \\
\hline
\end{tabular}

Note: *In authors personal experience.

Abbreviations: DSST, Digit Symbol Substitution Test; HAM-D, Hamilton Depression Rating Scale; HDS-R, Hasegawa Dementia Scale-Revised; MADRS, Montgomery-Åsberg Depression Rating Scale; MMSE, Mini-Mental State Examination; QIDS-J, Quick Inventory of Depressive Symptomatology-Japan; SDS, Zung Self-Rating Depression Scale; YMRS, Young Mania Rating Scale.

objective cognitive function, in conjunction with a patientreported questionnaire. $^{36}$ THINC-it has been developed to fulfill an unmet need for a reliable, valid, and sensitive assessment tool to evaluate cognitive function impairment in patients with MDD. Using a battery of domain-specific tests, THINC-it comprises four validated objective tests; nback memory task (Symbol Check), digit symbol substitution (CodeBreaker), trail making test - part-B (Trails), and choice reaction time (Spotter). These tasks test working memory, visuospatial coordination, set shifting and 
psychomotor speed. Subjective cognition is evaluated using a five-item Perceived Deficits Questionnaire (PDQ-D5). All of the components can be completed within 20 mins. THINC-it has demonstrated high levels of reliability and stability ${ }^{37}$ and validation has shown that subjective and objective cognitive function were impaired in patients with MDD relative to healthy controls. ${ }^{38}$

This study has several limitations. The key limitation of this study was that physicians were surveyed about which evaluation tools they acknowledged and used in general, and did not investigate their use of each evaluation tool for the phase of MDD, or at what stage in consultations, eg, initial or follow-up. Moreover, not all choices of evaluation tools for the assessment of cognitive dysfunction were included in the survey, eg, PDQ-D and the Brief Assessment of Cognition in Schizophrenia. Future studies may be required to determine what evaluation tools are used at different time points. This study was limited to physicians practicing in Japan, and moreover the target population may not be representative of all MDD-treating physicians in Japan because it was a web-based survey of an existing online database. Systematic bias and random variance may have occurred due to the questionnaire design (eg, ambiguous, confusing or biased questions and/or response options) or respondents (eg, misreporting true attitudes). Furthermore, $90 \%$ of the respondents were male, which may have created a bias toward the clinical preferences of male practitioners.

\section{Conclusion}

In conclusion, physicians in Japan acknowledge the importance and challenges of the diagnosis and management of cognitive dysfunction in patients with MDD. The majority of physicians reported a preference for a longer duration of physician-patient consultations for the diagnosis of MDD. There was a significant difference between hospital physicians and general practitioners regarding the ideal duration of initial consultation. Currently, it may be a challenge difficult for physicians to immediately implement longer consultations with their patients. Therefore, in the future, it may be useful to ensure collaborative team-based strategies whereby cognitive tests are administered by other practitioners such as a nurse, counselor, or pharmacist, or introduce digital tools such as THINC-it for the initial screening of cognitive dysfunction. ${ }^{38}$

\section{Ethics approval and informed consent}

All participants consented to the personal information protection law and their guidelines. All responses were anonymized and ethics approval was not required.

\section{Abbreviations}

DSST, Digit Symbol Substitution Test; ECG, electrocardiogram; EEG, electroencephalogram; HAM-D, Hamilton Depression Rating Scale; HDS-R, Hasegawa Dementia Scale-Revised; MADRS, Montgomery-Åsberg Depression Rating Scale; MDD, major depressive disorder; MMSE, Mini-Mental State Examination; PDQ-D, Perceived Deficits Questionnaire-Depression; QIDS-J, Quick Inventory of Depressive Symptomatology-Japan; SDS, Zung Self-Rating Depression Scale; YMRS, Young Mania Rating Scale.

\section{Data sharing statement}

Takeda makes patient-level, de-identified data sets and associated documents available after applicable marketing approvals and commercial availability have been received, an opportunity for the primary publication of the research has been allowed, and other criteria have been met as set forth in Takeda's Data Sharing Policy (see https://www.takedaclinicaltrials.com for details). To obtain access, researchers must submit a legitimate academic research proposal for adjudication by an independent review panel, who will review the scientific merit of the research and the requestor's qualifications and conflict of interest that can result in potential bias. Once approved, qualified researchers who sign a data sharing agreement are provided access to these data in a secure research environment.

\section{Acknowledgments}

The authors would like to thank the physicians who participated in this survey. They would like to thank Ms Manami Yoshida and Dr Shinzo Hiroi of Takeda Pharmaceutical Co. Ltd. (Tokyo, Japan) for their contribution in planning the study and development of the questionnaire, and acknowledge Mr Kohei Mizui and Mr Tomoyuki Kusaka of Social Survey Research Information Co. Ltd. (Tokyo, Japan) for their support in delivering the survey and statistical analysis. Medical writing support was provided by Mai Kurihara of Firekite, an Ashfield company, part of UDG Healthcare plc (Dublin, Ireland), which was funded by Takeda Pharmaceutical Co. Ltd., and complied with Good 
Publication Practice 3 ethical guidelines. This study was funded by Takeda Pharmaceutical Co. Ltd.

\section{Disclosure}

$\mathrm{HH}$ has received speaker's honoraria from Otsuka Pharmaceutical, Eli Lilly, Pfizer, Takeda Pharmaceutical Co. Ltd., Dainippon-Sumitomo Pharma, Meiji-Seika Pharma, Merck Sharp \& Dohme Pharma, and Janssen Pharmaceutical in the past 3 years. KY is an employee of Takeda Pharmaceutical Co. Ltd. The authors report no other conflicts of interest in this work.

\section{References}

1. Kessler RC, Bromet EJ. The epidemiology of depression across cultures. Annu Rev Public Health. 2013;34:119-138. doi:10.1146/ annurev-publhealth-031912-114409

2. Hasler G. Pathophysiology of depression: do we have any solid evidence of interest to clinicians? World Psychiatry. 2010;9(3):155161. doi:10.1002/wps.2010.9.issue-3

3. Okumura Y, Higuchi T. Cost of depression among adults in Japan. Prim Care Companion CNS Disord. 2011;13(3):PCC.10m01082. doi:10.4088/PCC.10m01072

4. Sato S, Yeh TL. Challenges in treating patients with major depressive disorder: the impact of biological and social factors. CNS Drugs. 2013;27(Suppl 1):S5-S10. doi:10.1007/s40263-012-0028-8

5. Furukawa TA, Kitamura T, Takahashi K. Treatment received by depressed patients in Japan and its determinants: naturalistic observation from a multi-center collaborative follow-up study. J Affect Disord. 2000;60(3):173-179. doi:10.1016/S0165-0327(99)00175-5

6. Ishikawa H, Kawakami N, Kessler RC, World Mental Health Japan Survey C. Lifetime and 12-month prevalence, severity and unmet need for treatment of common mental disorders in Japan: results from the final dataset of World Mental Health Japan Survey. Epidemiol Psychiatr Sci. 2016;25(3):217-229. doi:10.1017/S20457960150005 66

7. Ferrari AJ, Charlson FJ, Norman RE, et al. Burden of depressive disorders by country, sex, age, and year: findings from the global burden of disease study 2010. PLoS Med. 2013;10(11):e1001547. doi:10.1371/journal.pmed.1001547

8. World Health Organization. Depression and Other Common Mental Disorders: Global Health Estimates. Geneva: World Health Organization; 2017. Available from: http://apps.who.int/iris/bit stream/handle/10665/254610/WHO-MSD-MER-2017.2-eng.pdf.

Accessed October 15, 2018.

9. Ho SC, Chong HY, Chaiyakunapruk N, Tangiisuran B, Jacob SA. Clinical and economic impact of non-adherence to antidepressants in major depressive disorder: a systematic review. J Affect Disord. 2016;193:1-10. doi:10.1016/j.jad.2015.12.029

10. Alekhya P, Sriharsha M, Venkata Ramudu R, et al. Adherence to antidepressant therapy: sociodemographic factor wise distribution. Int J Pharm Clin Res. 2015;7(3):180-184.

11. Martín Vázquez M, García-Toro M, Campoamor F, Pareja A.Uso de los tratamientos antidepresivos. La percepción del paciente [Use of antidepressant treatments. Patient perception]. Actas Esp Psiquiatr. 2015;37(5):276-281. Spanish.

12. Martín Vázquez M, García-Toro M, Campoamor F, et al. Use and results of antidepressant treatment: patients' perception. Curr Drug Ther. 2011;6(4):271-277. doi:10.2174/157488511798109619

13. Sansone RA, Sansone LA. Antidepressant adherence: are patients taking their medications? Innov Clin Neurosci. 2012;9(5-6):41-46.
14. Tamburrino MB, Nagel RW, Chahal MK, Lynch DJ. Antidepressant medication adherence: a study of primary care patients. Prim Care Companion J Clin Psychiatry. 2009;11(5):205-211. doi:10.4088/ PCC.08m00694

15. Pompili M, Venturini P, Palermo M, et al. Mood disorders medications: predictors of nonadherence - review of the current literature. Expert Rev Neurother. 2013;13(7):809-825. doi:10.1586/14737175. 2013.811976

16. Lam RW, Kennedy SH, McLntyre RS, Khullar A. Cognitive dysfunction in major depressive disorder: effects on psychosocial functioning and implications for treatment. Can J Psychiatry. 2014;59(12):649654. doi:10.1177/070674371405901206

17. MacQueen GM, Memedovich KA. Cognitive dysfunction in major depression and bipolar disorder: assessment and treatment options. Psychiatry Clin Neurosci. 2017;71(1):18-27. doi:10.1111/pcn.2017. 71.issue-1

18. Papakostas GI, Ionescu DF. Updates and trends in the treatment of major depressive disorder. J Clin Psychiatry. 2014;75(12):14191421. doi:10.4088/JCP.14ac09610

19. Hammer-Helmich L, Haro JM, Jonsson B, et al. Functional impairment in patients with major depressive disorder: the 2-year PERFORM study. Neuropsychiatr Dis Treat. 2018;14:239-249. doi:10.2147/NDT.S146098

20. El Hammi E, Samp J, Remuzat C, et al. Difference of perceptions and evaluation of cognitive dysfunction in major depressive disorder patients across psychiatrists internationally. Ther Adv Psychopharmacol. 2014;4(1):22-29. doi:10.1177/2045125313507946

21. Knight MJ, Air T, Baune BT. The role of cognitive impairment in psychosocial functioning in remitted depression. J Affect Disord. 2018;235:129-134. doi:10.1016/j.jad.2018.04.051

22. Knight MJ, Baune BT. Executive function and spatial cognition mediate psychosocial dysfunction in major depressive disorder. Front Psychiatry. 2018;9:539. doi:10.3389/fpsyt.2018.00539

23. Knight MJ, Fourrier C, Lyrtzis E, et al. Cognitive deficits in the THINC-integrated tool (THINC-it) are associated with psychosocial dysfunction in patients with major depressive disorder. J Clin Psychiatry. 2018;80(1):18m12472. doi:10.4088/JCP.18m12472

24. Iga J-I, Uchiyama M, Ohmori T, et al. The Japanese Society of Mood Disorders Treatment Guideline. Tokyo: The Japanese Society of Mood Disorders Treatment; 2016. Available from: http://www.secre tariat.ne.jp/jsmd/mood_disorder/img/160731.pdf. Accessed October $15,2018$.

25. American Psychiatric Association. Diagnostic and Statistical Manual of Mental Disorders. 5th ed. Washington (DC): American Psychiatric Publishing; 2013.

26. Kennedy SH, Lam RW, McIntyre RS, et al. Canadian Network for Mood and Anxiety Treatments (CANMAT) 2016 clinical guidelines for the management of adults with major depressive disorder: section 3. Pharmacological treatments. Can J Psychiatry. 2016;61(9):540560. doi:10.1177/0706743716659417

27. National Institute for Health and Care Excellence. Depression in adults: recognition and management. 2018. Available from: https:// www.nice.org.uk/guidance/cg90. Accessed October 15, 2018.

28. Sumiyoshi T, Watanabe K, Noto S, Sakamoto S, Moriguchi Y, Okamoto S. Prospective epidemiological research on functioning outcomes related to major depressive disorder in Japan (PERFORM-J): protocol for a prospective cohort study. JMIR Res Protoc. 2018;7(6):e161. doi:10.2196/resprot.9682

29. Ragguett RM, Cha DS, Kakar R, Rosenblat JD, Lee Y, McIntyre RS. Assessing and measuring cognitive function in major depressive disorder. Evid Based Ment Health. 2016;19(4):106-109. doi:10.11 36/eb-2016-102456

30. Lam RW, Michalak EE, Bond DJ, Tam EM, Axler A, Yatham LN. Which depressive symptoms and medication side effects are perceived by patients as interfering most with occupational functioning? Depress Res Treat. 2012;2012:630206. 
31. Chokka P, Bougie J, Rampakakis E, Proulx J. Assessment in Work Productivity and the Relationship with Cognitive Symptoms (AtWoRC): primary analysis from a Canadian open-label study of vortioxetine in patients with major depressive disorder (MDD). CNS Spectr. 2018;24:1-10.

32. Liu X, Jiang K. Why is diagnosing MDD challenging? Shanghai Arch Psychiatry. 2016;28(6):343-345.

33. Gilmour G, Porcelli S, Bertaina-Anglade V, et al. Relating constructs of attention and working memory to social withdrawal in Alzheimer's disease and schizophrenia: issues regarding paradigm selection. Neurosci Biobehav Rev. 2019;97:47-69.

34. Baune BT, Sluth LB, Olsen CK. The effects of vortioxetine on cognitive performance in working patients with major depressive disorder: a short-term, randomized, double-blind, exploratory study. J Affect Disord. 2018;229:421-428. doi:10.1016/j.jad.2017.12.056

35. Jaeger J. Digit symbol substitution test: the case for sensitivity over specificity in neuropsychological testing. J Clin Psychopharmacol. 2018;38(5):513-519. doi:10.1097/JCP.0000000000000941

36. Progress in Mind - Psichiatry \& Neurology Resource Center. THINCit $^{\circledR}$ physician guide. 2017. Available from: https://progress.im/en/con tent/thinc-it\%C2\%AE-physician-guide. Accessed July 26, 2019.

37. Harrison JE, Barry H, Baune BT, et al. Stability, reliability, and validity of the THINC-it screening tool for cognitive impairment in depression: a psychometric exploration in healthy volunteers. Int $J$ Methods Psychiatr Res. 2018;27(3):e1736. doi:10.1002/mpr.1736
38. McIntyre RS, Best MW, Bowie CR, et al. The THINC-integrated tool (THINC-it) screening assessment for cognitive dysfunction: validation in patients with major depressive disorder. J Clin Psychiatry. 2017;78(7):873-881. doi:10.4088/JCP.16m11329

39. Ministry of Health Labour and Welfare Japan. Supplementary material: HDS-R evaluation sheet and supplementary explanation on the index of stratification [Japanese]. 2009. Available from: https:/www. mhlw.go.jp/topics/2009/05/d1/tp0501-sankou7-2.pdf. Accessed January 17, 2019.

40. Folstein MF, Folstein SE, McHugh PR. "Mini-mental state". A practical method for grading the cognitive state of patients for the clinician. J Psychiatr Res. 1975;12(3):189-198.

41. Tabuse H, Kalali A, Azuma H, et al. The new GRID Hamilton Rating Scale for Depression demonstrates excellent inter-rater reliability for inexperienced and experienced raters before and after training. Psychiatry Res. 2007;153(1):61-67. doi:10.1016/j.psychres.20 06.07.004

42. Naganuma H. Mood disorders: Manic episode [Japanese]. Rinsho Seishin Igaku. 1999;28(Suppl):128-134.

43. Japanese Society of Neurology. Guidelines for Neurological Examination. Tokyo: Japanese Society of Neurology; 2002. Available from: https://www.neurology-jp.org/news/news 20080715 01.html. Accessed November 15, 2018.

\section{Publish your work in this journal}

Neuropsychiatric Disease and Treatment is an international, peerreviewed journal of clinical therapeutics and pharmacology focusing on concise rapid reporting of clinical or pre-clinical studies on a range of neuropsychiatric and neurological disorders. This journal is indexed on PubMed Central, the 'PsycINFO' database and CAS, and is the official journal of The International Neuropsychiatric Association (INA). The manuscript management system is completely online and includes a very quick and fair peer-review system, which is all easy to use. Visit http://www.dovepress.com/testimonials.php to read real quotes from published authors. 